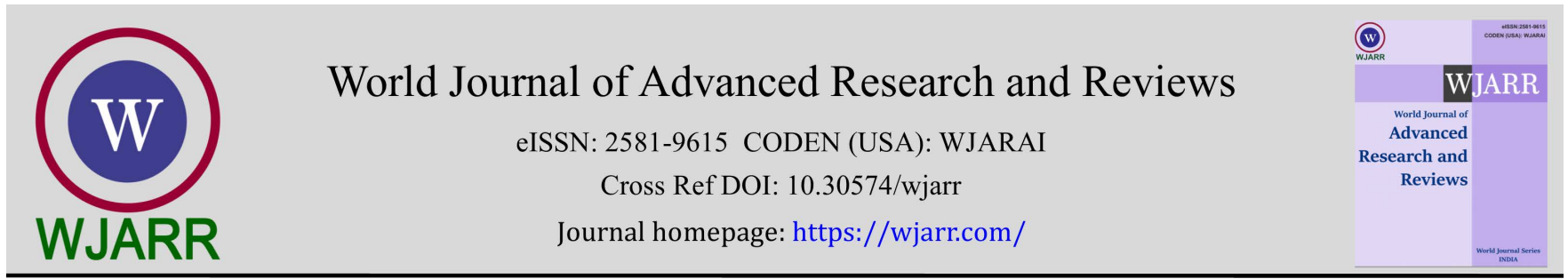

(RESEARCH ARTICLE)

\title{
Pharmacological action and physiological effect of the venom of the honey bee Apis mellifera Caucasica
}

\section{Lamiye YILDIZ*}

Tokat Gaziosmanpasha University, Medical Faculty, Department of Medical Physiology, Turkey.

World Journal of Advanced Research and Reviews, 2021, 12(03), 334-339

Publication history: Received on 22 October 2021; revised on 13 December 2021; accepted on 15 December 2021

Article DOI: https://doi.org/10.30574/wjarr.2021.12.3.0652

\begin{abstract}
The present's experimental data on the influence of the venom of the honey bee on the life span of experimental animals irradiated with small doses of gamma radiation on physiological and pharmacological action venom of the honey bee Apis mellifera Caucasica. The aim of the studies was to study the radioprotective effect of the pre-introduced venom Apis mellifera Caucasica with a single gamma irradiation of 60Co mice at doses of 1.3, 5, 7, 10 Gy at irradiation dose rates of $1 \mathrm{Gr} / \mathrm{min}$.
\end{abstract}

Injection of venom followed by gamma irradiation of $60 \mathrm{Co}$ at a dose of $\mathrm{D}=1,3,5$ and 7 Gy at an irradiation dose rate of $1 \mathrm{~Gy} / \mathrm{min}$ increased the life span of the experimental groups of mice ranging from $45 \%$ to $56 \%$ and from $52 \%$ to $67 \%$, respectively.

An increase in the lifespan of experimental rats exposed to radiation with the preliminary introduction of the venom of the honey bee.

Keywords: Honey bee; Apis mellifera Caucasica; Venom; Physiological; Pharmacological; Radioprotective action

\section{Introduction}

Growth of cancer - is a global trend. Cancer -is frequent disease worldwide. Stress and poor environment are the major causes of cancer. Initial treatment with chemotherapy and radiation therapy can reduce the size of the tumor. However, their use over a long period never lead to the destruction of the tumor and complete recovery. Therefore, search and research of effective natural sources, method of prevention and therapy of malignant tumors is one of the global and urgent problems of the world community. At present, more and more attention is drawn to drugs of natural origin, which include bee products. Every year researches of physiologists, biochemists and pharmacologists open new possibilities of influence of these valuable products of vital activity of bees on a human body. At present, more and more attention is drawn to drugs of natural origin, which include bee products. The use of bee venom and other bee products is widespread in the treatment of various diseases. Small doses of venom and their metabolic products have long been used in medical practice in the treatment of many diseases. Every year researches of physiologists, biochemists and pharmacologists open new possibilities of influence of these valuable products of vital activity of bees on a human body. The problem of antiradiation protection is becoming increasingly important in connection with the expansion of the use of ionizing radiation sources in various areas of human activity.

At the same time, to date, the list of pharmacological effects of bee venom has been significantly increased due to the disclosure of the physiological mechanisms of the action of bee venom on the human body $[1,2]$.

\footnotetext{
${ }^{*}$ Corresponding author: Ylldız LZ

Recep Tayyip Erdoğan University (RTEU), Medical Faculty, Department of Medical Physiology, Turkey.
} 
Important tasks of modern pharmacology are the search and development of new effective medicines for the prevention and treatment of various diseases, the study of the mechanisms of their action in animal experiments and the scientific rationale for rational schemes for their application. One of the most severe pathologies, requiring intensive pharmacotherapy and prevention, are radiation injuries arising from acute external radiation exposure $[3,4]$

Prevention of adverse effects of irradiation in hazardous doses to humans is achieved through the use of preventive anti-radiation means of radioprotectors. However, existing radioprotectors do not always meet the requirements for efficacy and tolerability $[5,6,7,8]$.

In this regard, both in our country and abroad, the search for new radioprotectors from various classes of chemical compounds, as well as compounds of natural origin, continues.

No less active is the study of the radioprotective action of zootoxins and preparations of animal origin.

Thus, analyzing the sources of modern literature, it should be noted that domestic and foreign scientists have studied the radioprotective properties of drugs from various pharmacological groups, but currently the search for radioprotectors is actively continuing. All this is due to the relatively low radioprotective efficacy of the substances studied, the toxic properties of radioprotectors and the inability to use them for a long time. However, it is necessary to note the prospects for solving this issue, which may be due to the combined use of radioprotective drugs from various pharmacological groups.

Like all poisons, bee venom has a general and local toxic effects, causing the destruction of red blood cells, reducing blood clotting by blocking the transmission of nerve impulse in the nodes, stimulating the function of the pituitary and adrenal glands. Bee venom is recommended in the treatment of several diseases. In recent years, it is also started to be used in oncology, as this is able to inhibit the growth poison cancer. Now, in many clinics and spas different methods of apitherapy - treating bees are used under the supervision of doctors [9].

It is possible radio protective action of venom of animals on processes of proliferation and a genetic material of bloodmaking cages practically has not been investigated. In the decision of the given problem, the important role belongs to search of radioprotective means of a natural origin. Zootoxins represent difficult, multicomponent mixes which can influence simultaneously many regulatory and executive systems of an organism and possess high biological activity.

On the basis of existing preconditions, authors have studied possibility of repeated operation of small (in ten times below lethal) doses of poisons of a bee melliferous (Apis mellifera), toads green (Bufo viridis) and salamanders spotty (Salamandra salamandra) for protection blood-making system of animals in the conditions of unitary and fractionated $\gamma$ - irradiations [10-14].

Many questions on impact of $\gamma$-radiation and other ionising radiation on a live organism and venom of bees remain open. These questions are important for technology of radiating sterilisation of medical products on the basis of venom of bees Apis mellifera L. Caucasica.

Proceeding from a few studies on the effect of bee venom on the life expectancy of experimental animals exposed to radiation a number of issues remain unexplored and is of great scientific and practical interest.

Analyzing the literature data on the degree of study of the venom of honey bees, the aim of the studies was to study the radioprotective effect of the pre-introduced zootoxin Apis mellifera Caucasica with a single gamma irradiation of 60Co mice at doses of 1.3, 5, 7, 10 Gy at irradiation dose rates of $1 \mathrm{Gr} / \mathrm{min}$.

\section{Material and methods}

The material of the study was ecologically pure whole poison collected from bees from apiaries, located on ecologically clean territory of Azerbaijan and venom irradiated with small doses of gamma radiation.

After taking, venom was stored in a desiccator over a couple of calcium chloride. Water solutions of venom were prepared immediately before the experiment. Many questions on impact of $\gamma$-radiation and other ionising radiation on a live organism and venom of bees remain open. These questions are important for technology of radiating sterilisation of medical products on the basis of venom of bees Apis mellifera L. Caucasica. 


\section{The results of the research and their discussion}

Proceeding from the above, the bee venom dissolved in physiological solution in a dose of $0.1 \mu \mathrm{g} / \mathrm{kg}, 0.2 \mu \mathrm{g} / \mathrm{kg}, 0.5 \mu \mathrm{g}$ / $\mathrm{kg}, 1.0 \mu \mathrm{g} / \mathrm{kg}$ and $2.0 \mu \mathrm{g} / \mathrm{kg}$ was injected to animals of control groups to study the radioprotective action of the bee venom. A single total $\gamma$-irradiation of $60 \mathrm{Co}$ mice was carried out in doses of $\mathrm{D}=1,2,3,5,7$ Gy at irradiation dose rate of $1 \mathrm{~Gy} / \mathrm{min}$. The experiments were carried out in 5 series of experiments in vitro.

We have considered the prevention of radiation damage to experimental animals by venom of the honey bee that occurs when external mice are irradiated.

In order to study the radioprotective effect of the honey bee venom, a control group of mice was irradiated at $\mathrm{D}=1,3$, 5 , and 7 Gy.

Experimental groups of 2-3-month-old white mongrel mice with a total body weight of 18-22 grams were first intraperitoneally injected with bee venom at a dose of $0.01,0.02,0.04$ and $0.05 \mathrm{mg} / \mathrm{kg}$ of body weight, 3 days at a frequency of once a day.

Then, the first experimental group of mice was subjected to a single gamma irradiation of 60 Co in a dose of D = 1 Gy at a dose rate of $1 \mathrm{~Gy} / \mathrm{min}$ after 3 days, the second experimental group of mice after 3 days subjected to a single gamma irradiation of $60 \mathrm{Co}$ in a dose of $\mathrm{D}=3 \mathrm{~Gy}$ at a radiation dose rate of $1 \mathrm{~Gy} / \mathrm{min}$.

The third experimental group of mice was subjected to a single $\gamma$-irradiation of $60 \mathrm{Co}$ in a dose of D $=5 \mathrm{~Gy}$ at a dose rate of $1 \mathrm{~Gy} / \mathrm{min} 3$ days after irradiation, and the fourth experimental group of mice, 3 days after irradiation, subjected to single $60 \mathrm{Co} \gamma$-irradiation at a dose of $\mathrm{D}=7 \mathrm{~Gy}$ radiation at a dose rate of $1 \mathrm{~Gy} / \mathrm{min}$, the fifth experimental group of mice 3 days later were subjected to single $60 \mathrm{Co} \gamma$-irradiation at a dose of $\mathrm{D}=10 \mathrm{~Gy}$ radiation at a dose rate of $1 \mathrm{~Gy} / \mathrm{min}$.

The survival of mice with intraperitoneal injection of bee venom at a dose of $0.01,0.02,0.04$ and $0.05 \mathrm{mg} / \mathrm{kg}$ of body weight followed by a single $\gamma$-irradiation of $60 \mathrm{Co}$ in a dose of $\mathrm{D}=1 \mathrm{~Gy}$ at a dose rate of $1 \mathrm{~Gy} / \mathrm{min}$ is given in Figure 1 .

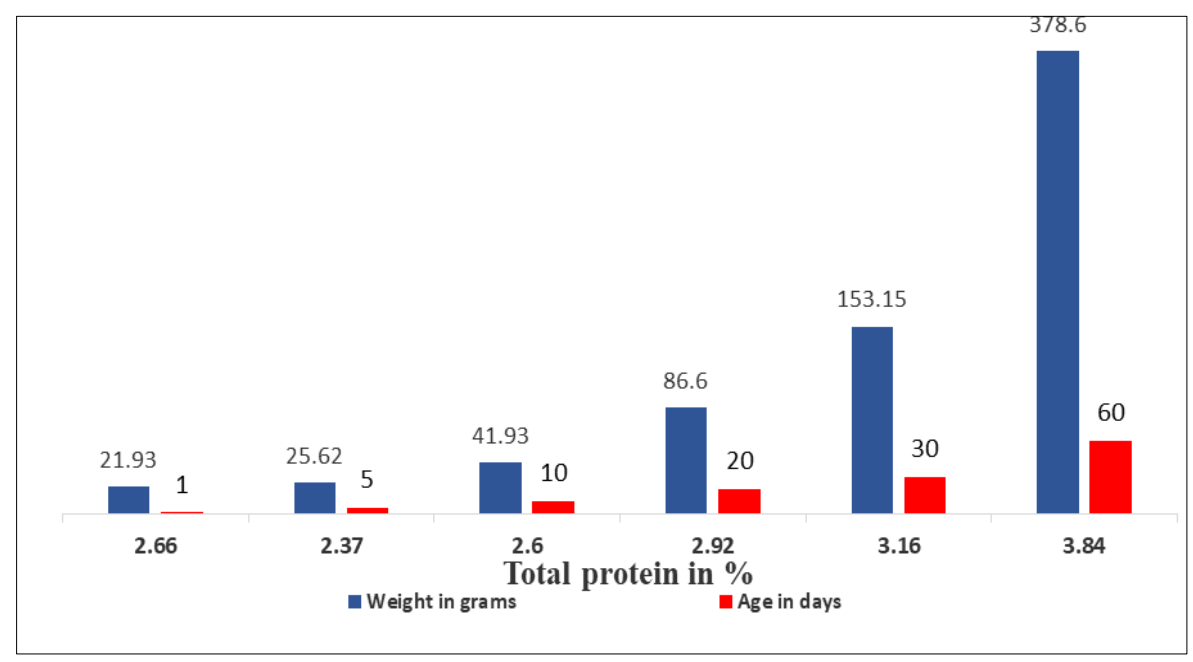

Figure 1 The survival of mice with intraperitoneal injection of bee venom at a dose of 0.01; 0.02; $0.04 \mathrm{and} 0.05 \mathrm{mg} / \mathrm{kg}$ of body weight followed by a single $\gamma$-irradiation of 60Co at a dose of D 1 Gy, $3 \mathrm{~Gy}, 5 \mathrm{~Gy}, 7 \mathrm{~Gy}$ at a dose rate of $1 \mathrm{~Gy} / \mathrm{min}$

The following 5, 6, 7, and 8 groups of experimental mice were injected intramuscularly with bee venom at a dose of 0.1 $\mathrm{mg} / \mathrm{kg}$ body weight followed by a single $\gamma$-irradiation of $60 \mathrm{Co}$ irradiation at a dose of D = 1 Gy at dose rate of $1 \mathrm{~Gy} / \mathrm{min}$.

The survival of mice with intramuscular injection of bee venom at a dose of $0.01,0.02,0.04$, and $0.05 \mathrm{mg} / \mathrm{kg}$ of body weight followed by a single $\gamma$-irradiation of $60 \mathrm{Co}$ at a dose of $1,3,5$ and 7 Gy at an irradiation dose rate of 1 Gy $/ \mathrm{min}$ is given in Figure 2.

The following 9, 10,11, 12, and 13 groups of experimental mice were injected intraperitoneally with bee venom at a dose of $0.01,0.02,0.04$ and $0.05 \mathrm{mg} / \mathrm{kg}$ of body weight after a day, subjected to a single gamma irradiation of $60 \mathrm{Co}$ at a dose of $\mathrm{D}=1,3,5$ and $7 \mathrm{~Gy}$ at an irradiation dose rate of $1 \mathrm{~Gy} / \mathrm{min}$. 
The survival rate of mice with intraperitoneal injection of bee venom at a dose of $0.01,0.02,0.04$ and $0.05 \mathrm{mg} / \mathrm{kg}$ of body weight, followed by (after one day) by a single gamma irradiation of 60Co at a dose of D =1, 3, 5 and 7 Gy at an irradiation dose rate of $1 \mathrm{~Gy} / \mathrm{min}$ is shown in Figure 3

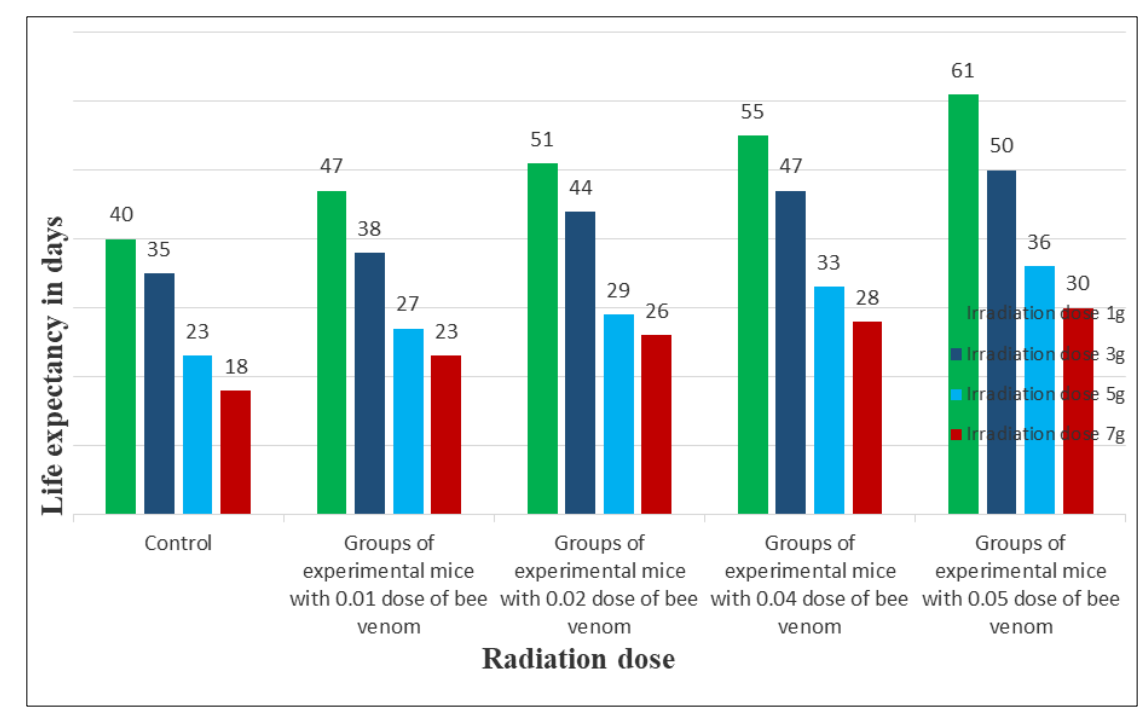

Figure 2 The survival rate of mice with intramuscular injection of bee venom at a dose of $0.01,0.02,0.04$ and $0.05 \mathrm{mg}$ / $\mathrm{kg}$ of body weight followed by a single $\gamma$-irradiation of $60 \mathrm{Co}$ at a dose of $\mathrm{D}=1,3,5$ and 7 Gy at an irradiation dose rate of $1 \mathrm{~Gy} / \mathrm{min}$

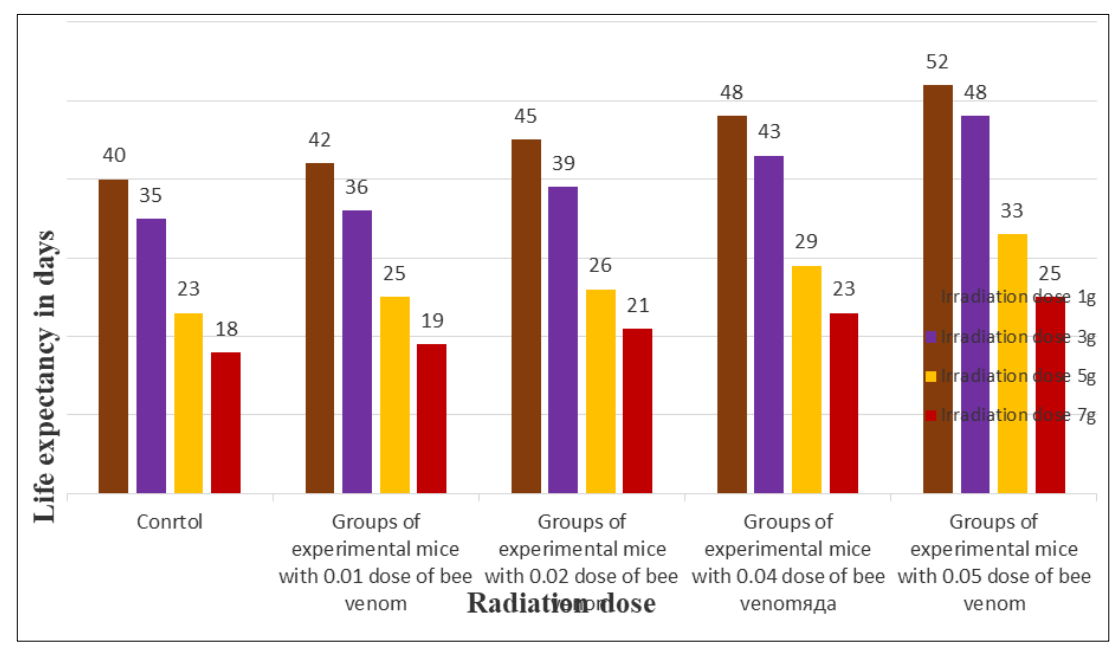

Figure 3 The survival rate of mice with intraperitoneal injection of bee venom at a dose of 0.01, 0.02, 0.04 and $0.05 \mathrm{mg}$ / kg of body weight, followed by (after one day) by a single gamma irradiation of 60 Co at a dose of $\mathrm{D}=1,3,5$ and 7 Gy at an irradiation dose rate of $1 \mathrm{~Gy} / \mathrm{min}$

The following 14, 15, 16, and 17 experimental groups were intramuscularly injected with bee venom at a dose of 0.01 , $0.02,0.04$ and $0.05 \mathrm{mg} / \mathrm{kg}$ of body weight after a day, subjected to single $\gamma$-irradiation of $60 \mathrm{Co}$ at a dose of D = 1, 3, 5 and 7 Gy at Dose rate of 1 Gy / min.

The survival of mice with intramuscular injection of bee venom at a dose of 0.01, 0.02, 0.04 and $0.05 \mathrm{mg} / \mathrm{kg}$ of body weight with a single (after a day) $\gamma$-irradiation of $60 \mathrm{Co}$ in a dose of $\mathrm{D}=1,3,5$ and 7 Gy at a dose rate of $1 \mathrm{~Gy} / \mathrm{min}$ are given in Figure 4. 
An increase in the total number of surviving animals was noted in all the groups studied, but the nature of the change in the lifespan of mice differs both from the method of administration and from the time of administration of the poison after gamma irradiation of 60 Co.

In experiments on mice with intraperitoneal or intramuscular fractional injection of venom followed by a single $\gamma$ irradiation of $60 \mathrm{Co}$ at a dose of $\mathrm{A}=1,3,5$ and $7 \mathrm{~Gy}$, an increase in the lifespan of experimental groups of mice was noted at an irradiation dose rate of $1 \mathrm{~Gy} / \mathrm{min}$.

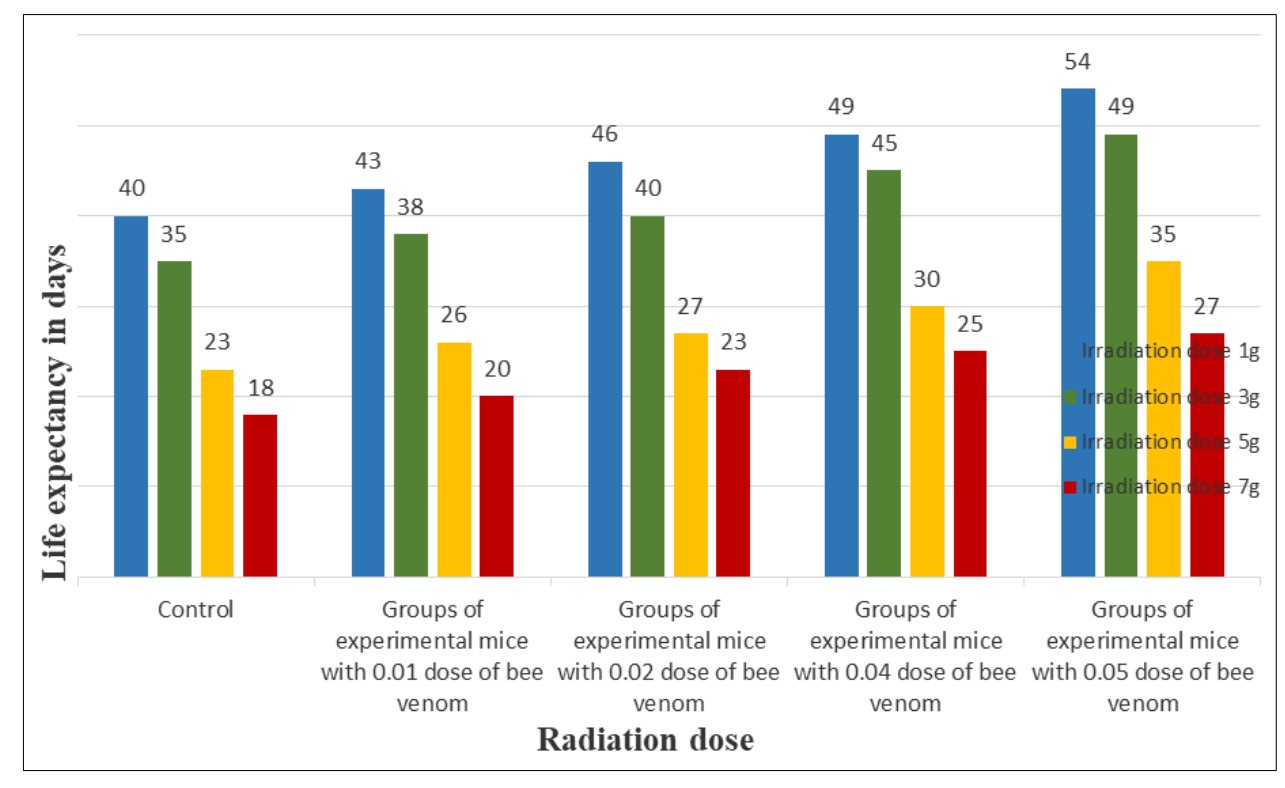

Figure 4 The survival rate of mice with intramuscular injection of bee venom at a dose of $0.01,0.02,0.04$ and $0.05 \mathrm{mg}$ / $\mathrm{kg}$ of body weight with a single (after a day) $\gamma$-irradiation of $60 \mathrm{Co}$ at a dose of $\mathrm{D}=1,3,5$ and 7 Gy at an irradiation dose rate of $1 \mathrm{~Gy} / \mathrm{min}$

The survival rate of the experimental groups of mice, in relation to the control group, ranged from $45 \%$ to $56 \%$ and from $52 \%$ to $67 \%$, respectively.

Survival of the experimental groups of mice, with respect to the control group with a single intraperitoneal or intramuscular injection, increased within the range of $30 \%$ to $39 \%$ and $35 \%$ to $50 \%$, respectively, 24 hours after the injection of venom.

We believe that the radioprotective effect of bee venom is associated with the formation of a nonspecific adaptation reaction.

Thus, we detected a radioprotective effect of the honey bee venom, which manifests itself in an increase in the lifespan of experimental animals subjected to $\gamma$-irradiation of ${ }^{60} \mathrm{Co}$.

For the first time it was revealed that the injection of venom is accompanied by a prolonged radioresistance, reducing the effect of ionizing radiation on the life span of mice under conditions of a single gamma irradiation.

Consecutive introduction of bee venom to radiation exposure and in the early periods after irradiation allows to increase the survival time of experimental animals subjected to irradiation.

Investigation of the radioprotective effect of the course injection of small doses of bee venom under conditions of a single fractionated gamma irradiation makes it possible to broaden the notion of nonspecific radioresistance and suggests the possibility of creating new preparations on the basis of biologically active substances of animal origin that enhance the radioresistance of the organism.

The practical significance of using bee venom in small doses is that they can be considered as a drug of choice in conditions of fractionated and, possibly, chronic exposure to ionizing radiation. 
Radioresistance, which develops in the body in response to multiple injections of bee venom, can successfully protect the body from fractionated gamma irradiation.

\section{Conclusion}

- The increase in the lifespan of mice differs from the method of injection, and the time of injection of the venom after $\gamma$-irradiation.

- Intraperitoneal or intramuscular fractional injection of venom followed by a single gamma irradiation of $60 \mathrm{Co}$ at a dose of $\mathrm{D}=1,3,5$ and $7 \mathrm{~Gy}$ at an irradiation dose rate of $1 \mathrm{~Gy} / \mathrm{min}$ increased the life span of the experimental groups of mice ranging from $45 \%$ to $56 \%$ And from $52 \%$ to $67 \%$.

- At a single (after 24 hours) intraperitoneal or intramuscular injection of the venom, the life span of the experimental groups of mice increased from $30 \%$ to $39 \%$ and from $35 \%$ to $50 \%$, respectively.

\section{Compliance with ethical standards}

\section{Acknowledgments}

Author would like to thanks the team of doctors of the National Academy of Sciences of Azerbaijan.

\section{Disclosure of conflict of interest}

None of the material in this manuscript has been published previously in any form and none of the material is currently under consideration for publication elsewhere other than noted in the cover letter to the editor. The author declare that the research was conducted in the absence of any commercial or financial relationships that could be construed as a potential conflict of interest.

\section{References}

[1] http://www.unn.ru/site/about/news/uchjonye-nngu-izuchayut-voprosy-vliyaniya-pchelinogo-yada-nazhivye-organizmy.

[2] Krylov VN, Mljavyj V Venom of bee in scientific and practical medicine. (Monography). "Tehnoprint". $2002 ; 266$.

[3] Vasin MV. Antiradiation drugs. GIUV MO RF. 2010; 180.

[4] Zalyalyutdinova LN. Study of the influence of a new lithium amino acid complex on the post-radiation restoration of hematopoies in the experiment. Fundam. Issled. 2005; 8: 34-35.

[5] Karkishchenko HH. Fundamentals of Biomodeling. Moscow: Publishing House of the Military Industrial Complex, 2004; 607.

[6] Nazarov VB. Current state and prospects for the production of anti-radiation drugs and antidotes in the Russian Federation. Vestn. Ros. Military-medical. Academy. 2008; 3(23): 48-54.

[7] Mackova NO. Recovery of peripheral blood cells in irradiated mice pretreated with bacterial extract IRS-19, Physiol. Res. 2000; 49(6): 703-710.

[8] Song JY. Radioprotective effects of Ginsan, an immunomodulator. Radiat. Res. 2003; 15(9): 768774.

[9] Grebenyuk AN. Principles, means and methods of medical Radiation Protection. Medicine of catastrophes. 2007; 3(59): 32-35.

[10] Orslic N. Bee venom in cancer therapy. Cancer Metastasis Rev. 2012; 31(1-2): 173-94.

[11] Jedryszyk A. Bees and products beekeeping as an indicator of soiling a surroundings. Med. Weter. 1987; 43(6): 352-356.

[12] Grobov OF. Bee’s environmental indicators. Beekeeping. 1989; 12: 3-5.

[13] Kadirov RA. Bee products as indicators of environmental pollution with heavy metals. Proceedings of the conference. "Environmental issues management and production of quality products. Moscow, Chelyabinsk. 1999; 84-86.

[14] Krylov VN. Apitoxin - what is it? Beekeeping. 1993; 2: 36-39. 